THE LANCET, APRIL 19, 1845.

\section{INTRODUCTORY ADDRESS,}

\author{
DELIVERED AT THE
}

SCHOOL OF MEDICINE, PARK-STREET, DUBLIN, 1845.

By R. W. WILdE, Esq., M.R.S.A., F.R.C.S. \&c.,

SURGEON TO ST. MARK'S OPHTHALMIC HOSPITAL, AND LECTURER ON DISEASES OF THE ETE AND EAR.

THE ORGANS OF SIGHT AND HEARING.

Gentlenen,-A Course of Lectures upon the diseases of the organs of sight and hearing demands your special attention, from their great importance in a practical point of view, from their exceeding beauty, and the unrivalled perfection of the minute anatomical construction of these organs; from the high order of sense with which they endow mankind, and, above all, from the necessity of their being in a perfectly healthy condition, not only to insure the comforts and the enjoyment of all, but the actual existence and support of so large a portion of our fellow-creatures.

Few are there, even among the general public, or as it is termed, the popular portion of the community, who have not some tolerably correct idea of the physiology of touch, of how sensations are received upon, and afterwards conveyed from, the expanded end of a nervous filament to the great centre, or cerebrospinal axis; of how odoriferous bodies affect the fine nervous material upon the mucous or Schneiderian membrane of the nose and frontal sinuses, and are from thence conveyed to the brain; of the effect which sapid, sweet, saline, pungent, or such like substances, produce upon the same deseription of organization of the tongue, lips, and mouth-all modifications, however, of the same universal sense of touch, and all faculties which may be impaired, or even lost, without materially interfering with man's health, his enjoyments, or his means of acquiring his livelihood. But how far superior in organization, functions, and endowments, are the two other great senses, sight and hearing, to those which I have mentioned, it requires neither the efforts nor the eloquence of a lecturer of the present day to inform you.

Occupying so prominent a position among the three other most essential senses, surrounded by all that gives life and expression to the external impress of man's intellectuality and noble bearing, the eye, more than either voice, or feature, or general appearance, arrests and rivets our attention, and often at a transient interview, or even a single glance, calls forth our pity, excites our disgust, awakens our alarm, or imperatively commands our respect, and speaks to us in a language more forcible and more truth-telling than words.

This wonderful power, with which you are all more or less familiar, is not alone the attribute of man, its range and its effect is only terminated by the limits of the visual organs among the lower animals. Gro into the wild scenes of savage life, the forest, the prairie, or the jungle,--do you not there read the habits, the dispositions, and the tempers of the brute creation, in the watching eye of the lynx; the prowling treachery of the tiger; the timidity of the hare and gazelle; the mild, impressive calmness and innocence of the giraffe; the inactivity of the sloth; the firmness, yet docility, of the elephant; and the proud daring of the eagle?

How great the value of these organs to man, and how wonderful their effect, no pen or language can fully describe. In him all the kaleiduscope powers of the lower animals are combined and varied, to give fire to the orator, passion to the poet, command to the warrior, quickness and subtlety to the casuist, and love and gentleness to woman.

It was said by Talleyrand, that in diplomacy the use of words was to cloak the real feelings of the heart. But I would add, that to do so with effect, he should have covered the eye, or educated it in like manner with the tongue. The two senses of sight and hearing form the great inlets to knowledge, and by their aid we hold communion with external nature. By the perfection of these, poetry, music, and painting, with its handmaids, sculpture and architecture, become our inheritance, and without them we are reduced to a state really little higher than that of vegetable existence; for speech, the chief characteristic of our species, and perhaps the most decided attribute of man, ceases to exist, or is never developed, when the latter faculty, that of hearing, is deficient. How great this loss, how awful this privation, we learn from the curious and interesting details lately brought before the public, of those who are either born, or shortly after birth become, deaf, dumb, and blind. How touchingly, and with what mournful pathos, does the great Milton embody his own sufferings and privations in these beautiful lines:-

No. 1129.

\section{“Thus with the year}

Seasons return; but not to me return

Day, or the sweet approach of eve or morn,

Or sight of vernal bioom, or summer's rose,

Or flocks, or herds, or human face divine ;

But cloud instead," \&c. \&c.

with which all readers of English poetry are familiar.

How wonderfully the power of vision is varied, and how admirably adapted to the circurnstances of all, comparative anatorny, zoology, and observation of the lower animals, afford innumerable proofs.

The eagle and his species soar into the regions of the clouds, and proudly gaze upon the sun in the full effulgence of his noonday glory; the feline tribe and the nocturnal raptores seek their prey amid scenes where all is utter darkness to man; the mole burrows beneath the surface of the earth, and steadily pursues its way to the object of its attention; the cetacea and hundreds of fishes thrive at depths beneath the ocean surface, where no doubt light must undergo peculiar modifications. In the many-lensed organs of the insect tribe, do we not find an arrangement, do we not observe a faculty, of minute vision that is in itself a study; and among the animals of a former world, where light, heat, and the very constitution of our atmosphere were in all probability so different to what they now are, do we not find, in their fossil remains, curious structures in the visual apparatus of those extraordinary creatures, the ichthiosauri, plesiosauri, and pterodactyles, to fit them to the medium in which they lived! But in man, gentlemen, the two great perfections of sight are combined. With his telescopic eye he takes in at a glance hundreds of miles of nature's landscape, or counts the nebulm in the starry firmament, thousands, nay, millions of miles above his head; and with his microscopic eye he can (even as in the former case, without the aid of instruments) examine and unravel the most complicated anatomical arrangement, or perform the most delicate manipulation in the arts.

As, then, in man's eye in health we read his character, and in those mirrors of his mind find an index to his inmost and unspoken thoughts, so in disease, physical and moral, do we, by the same means, observe the frenzy of the maniac, the sensuality of the glutton, the languor of the hypochondriac, the vacant stare of the idiot, or of persons labouring under cerebral affections, the heavy lacklustre appearance in those suffering from derangement of the digestive functions, and so on, sympathizing mentally and corporally with most of, if not all, the ills to which humanity is heir. In fine, " as man," says the great father of modern ophthalmalogy, " in relation to the universe, must be regarded as a little world, so must we consider the eye, in relation to the individual man, as a microphthalmus, in which his soul and body are reflected."

There is, moreover, no other organ which, from the peculiarity of its construction, affords us better opportunities of studying the phenomena of disease than the eye. Have we not there all the varieties of inflammation better marked than in other parts, and, moreover, going forward beneath our gaze? Have we not there every morbid change, even of internal structures, taking placè in tissues which, from their transparency, allow us to observe and study their progress and effect? Where have we a better opportunity of witnessing the peculiarities of the yascularity of the catarrhal, the syphilitic, the rhematic, the gouty, and numerous other specific and non-specific inflammation that 1 might mention, than in the eye?. Where do we see synovial membranes thicken, become opaque and vascular, and have lymph deposited on the surface, but in the eye? Do we not, then, learn many practically useful lessons from these analogies? Assuredly we do; for there, and there alone, are we able to explain the particularity of inflammations and other morbid actions occurring in, and modified, increased, or altered by, the several fibrous, mucous, serous, muscular, glandular, and other tissues that enter into the composition of our frames, but which, when concealed from our view, as in the cavities of the head, chest, abdomen, or joints, we can only diagnose by our other senses, and by symptoms often vague and uncertain.

How valuable is our knowledge of the state, condition, and appearance of the eye in its sympathy with several vital and important organs, with the liver, the stomach, the uterus, and the brain! How frequently are the symptoms first presented by the eye indicative of the incipient state of derangement of these organs, and how frequently are they precursors of some great morbid change in them! For instance, you are called on to see a case of sudden, partial, or total loss of vision; the eye looks $m u d d y$, the iris is sluggish, the pupil is contracted, or but slightly dilatable, the conjunctiva assumes a yellow hue, and is traversed by large brick-coloured vessels, assuming an interrupted zonular character around the cornea; the upper eyelid is slightly affected with ptosis; there is some intolerance of light, 
notwithstanding the loss of vision, and the patient suffers but little pain or uneasiness; yet all this is strongly indicative of approaching cerebral disease, when as yet no other symptom has manifested itself.

I was lately consulted bv a gentleman on account of very slight strabismus, but very manifest double vision. In other respects he was in perfect health when I first saw him, but the double vision and strabismus had come on within a few days. With much diffculty he could be persuaded to submit to treatment of any description, but very shortly after, mauifest disease of the brain ensued, which, however, yielded to treatment, and after several weeks' careful watching, he has so far recovered as to be able to return to his usual active mental occupations. In this case $I$ do believe, but from the timely warning given by the eye, matters might have ended differently. Again: in injuries of the head, how much do we not learn of the condition of the patient from the state of this organ. But time will not permit me to enlarge further on this topic.

Gentlemen, - There is no other department of medicine in which you may so soon gain or lose a cliaracter, as in ophthalmic surgery. Most of you will shortly return to your homes in the country; now, as there is no village in Ireland in which there are ten or a dozen old women without some of them being affected with a disease of the eye, or its appendares, your opportunities of treating such will be numerous. Suppose you cure one of these old ladies, what is your reward? Why, she tells you that she will never cease to pray for your welfare. How far these prayers may affect you, here or hereafter, I will not pretend to say; but this I will take upon myself to state, that unless she differs very much from all other old women, she will talk your character into considerable notice in that parish or district. Here, then, is the commencement of your reputation, and believe me, many a one has been gained upon as slender pretensions.

What, then, is your next case? Perhaps you are called in to see the squire of the parish, or the lord of the manor; he has got an inflamed eye. Now, suppose it to be an iritis-what does it proceed from; whether from gout, scrofula, rheumatism, or yphilis, you do not know. Your treatment of bleeding, blistering, and physicking, has no permanent or decided effect; the eye goes on from bad to worse: the pupil becomes contracted, and the iris adherent; vision is considerably impaired, and the constitution suffers with the local afiection. The friends of the patient become alarmed, they cease to have confidence in your skill, and he is taken off either to the city or some large provincial town, to have further advice from some more intelligent surgeon or special oculist; and there he finds out, by some means or other, that he has been badly treated, and the blame is laid at your door.

Here, then, is your character lost. I would not advise you to look for a dispensary or an hospital in that part of the country. Now you might have allowed this gentleman to die. I will not say you might have killed him with impunity, but you have decidedly done worse for your reputation, for his blindness will remain an eyesore to you while you continue to reside in that neighbourhood.

This brings us to one of the most essential requisites in treating ophthalmic diseases - the faculty of making an early diagnosis. It will not do to know that a man has an inflamed eye-an ophthalmia; an inflammation of the conjunctiva or the sclerotic, or of the choroid or the iris; not only must the particular part which is inflamed be accurately observed, but the particular causes, whether local, general, or specific, must be all inquired into, and the case treated accordingly.

I may here mention that I know scarcely one well-established or distinguished country practitioner in Ireland, who has not had some reputation as an ophthalmic surgeon. Again: should any of you enter into either the army or navy, I need not dwell upon the advantage of your possessing some ophthalmic knowledge, for in such case it becomes an indispensable requisite. "The troops under your care are frequently ordered to warro countries, where, as most of you are aware, diseases of the eye become epidemic, and attack whole regiments together. The frightiful ravages which an ophthalmia committed among the British army at the commencement of this century, has become a matter of history; and some idea may be formed of an epidemic and contagious inflammation of the conjunctiva, when I tell you that I have seen no less than 500 patients affected with Egyptian ophthalmia in its different stages, either within the wards of, or in attendance at, the om at Military Hospital of Abouzabel, near Cairo, on the same morning: Remember, then, the great trust which is committed to you in this particular, and bear in mind that every case of ophthalmia which, either from your ignorance or neglect, ends in partial or total loss of vision, entails upon your country the expense of supporting the individual so affected during his lifetime. "If" says Mr. Lawrence, "there are any to whom the pleasure connected with the acquisition of knowledge, the satisfaction flowing from consciousness of important duties rightly performed, and the gratitude so warmly expressed for the inestimable benefit of averting blindness or restoring sight, should not prove an incentive sufficiently powerful to the study of ophthalmic medicine and surgery, their case must be deemed desperate; unless, indeed, their minds, insensible to higher fielings and nobler motives, should obey the impulse of self-interest and fear; unless they should be affected by the prospect of disgrace and injury, which ignorance and its inseparable blunders must entail. The consequences of wrong treatment cannot be concealed here, as in the obscure affections of internal organs; the visible changes of structure are obvious to the external observation, and the unfortunate individual whose sight is injured or destroyed by unskilful treatment, serves as a lasting memorial of the incapacity and rashness to which he owes his misfortune."

The study of diseases of the eye is, therefore, now justly regarded as an essential part of general medical education; but it is more particularly so to the country practitioners, who are thrown entirely on their own resources; who cannot, as in the metropolis and some large cities, call in the aid of superior talent and knowledge.

Above all, let me impress upon you, that many of the diseases of the eye, such as malignant fungus, melanosis, and cancer, \&c., are matters of life and death, where an early diagnosis is frequently the patient's only chance.

In such cases, you cannot be too cautious, and if you do err, let it be on the right side.

Here is the drawing of the eyes of an infant, sent up from a distant part of the country to be operated on for cataract. It turned out, however, to be fungus hxmatodes in the end of the first stage; and yet of the practitioner who sent it up, both as a skilful surgeon, an educated and most astute physician, and as a man in whose hands I would most willingly place ny own life, if necessary, to-morrow, I need not tell you I entertain the very highest opinion. By early diarnosing such a case, an operation may, at a particular period, be conscientiously resorted to, but if you let that period pass by, the case is hopeless. If we err in the first point, and the case turns out favourably, we may offend the patient, or his friends, and we may feel mortifed at the error of our judgment, though, I am sure, rejoiced at the result. If the case turns out fortunately, we injure but ourselves; but if such a case comes in the end to be malignant, and we have every reason to believe, or to fear, such an issue, then, if we do not warn the friends, or the patient, we are undoubtedly reprehensible.

Bear in mind the numberless injuries and accidents to which this organ, from its position, is exposed, parcicularly in a manufacturing country like Great Britain. Gentlemen, consider of these matters, and then let any one tell me that he is capable of undertaking the medical care and superintendence of a regiment, a ship, an hospital, or any institution, or that he is fit to go into practice in any of the wallss of our profession, without a knowledge of the diseases of the eye.

This country, I regret to say, affords but too many opportunities for studying diseases of the eye, owing to the peculiar variableness of our climate, the reckless character of our population, the very great prevalence of scrofula, the poverty, dirt, and misery, and destitution, of our people, particularly in large cities like this, the bad feeding, the bad clothing, the exposure, and late hours, and the overworked condition of some of the feeblest part of our community, whose minds and bodies are enslaved and chained to the god of wealth; who may, with the buoyant elastic spirit peculiar to our nation, rise ont of sorrow or affliction with even a word of sympathy or of lindness, but whose naked and worn frames sink and wither under privation and disease!

Why do I recount these miseries? How do they cross the path of the oculist? Go into any ophthalmic institution, look around you there, and see how many sempstresses, milliners, and shirt-makers, stand around, of all ages, but chiefly young women from eighteen to twenty-five, pale with watching, haggard with working sixteen hours a day for $3 s .6 d$. or $4 s$. per week, cold, and perhaps hungry, and nearly blind with stitching for the votaries of fashion.

How admirably told is this condition in the melancholy but truthful song of THE SHIRT:-

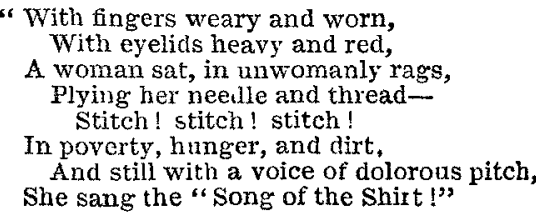

Every man who teaches medicine-every man who practises 
medicine-every medical student-is, more or less, a guardian of the public health. He, and he alone, sees the conditions I have described; and he alone knows the truth and value of these assertions, and therefore it is his duty to raise his voice, each in his own particular sphere, against those evils which Mammon has raised up amongst us. These matters cannot be too frequently or too forcibly put before the mind of a public, that will, I know, lean to the side of humanity, when it sees good reason for exerting its benevolence.

In concluding this portion of my subject, a question proposes itself-Ought ophthalmic surgery to be made a speciality, or a separate and distinct branch of medicine? If by such is meant the separating that art from a general acquaintance with medicine and surgery, and studying the eye and its diseases locally, or per se, I would answer, certainly not. A man may extract, or couch a cataract with great adroitness and success, make an artificial pupil, or cut for a squint, and be, after all, no oculist, because he is no physician, no general surgeon.

If by the term oculist we mean a person who knows the diseases and operations on the eye, who is educated in the various morbid appearances which it presents, and even possesses an acquaintance with the anatomy of the organ, but who, from knowing nothing else, devotes his time exclusively to the affections of this organ; then let me tell you, gentlemen, the usefulness and power of such a person is very much overrated. That the minute subdivision of labour tends to produce perfection in art, all modern investigation tends to confirm. In the medical profession this holds good equally as in art, and in no branch is it so fully appreciated as in diseases of the eye.

Mr. Veitch very justly observes on this suhject-" To limit the spiere of science by the detachment of its parts, is to destroy the foundation upon which it rests. With respect to that of medicine, however beneficially we may observe the labours of individuals to be occasionally exerted in the selection of particular branches, as the more exclusive objects of their study and attention, yet this can only occur to those who have first investigated this science as $a$ whole; and we may be assured that others, who assume a superior knowledge of any branch of medical practice on the grouad of a comparative ignorance of, or indifference to, the rest, are but little indebted for whatever reputation they acquire to the actual benefit they are able to effect." The same principles were adrocated by Mr. Samuel Cooper, upwards of thirty years ago, while Mr. Travers, as would appear from his writincs, fell into the opposite extreme, by asserting that he only made the oculist who was at the same time engaged in the treatment of other diseases.

Ouyht ophthalmic surgery to be a separate branch of education as it is of practice? Ought there to be separate lectures and separate hospitals in which to study it? Yes, because students cannot learn diseases of the eye suficiently in our general hos. pitals. Look to those where wards are even set apart for this purpose, and tell me how many ophthalmic diseases can one learn in six months? Again, unless men are in the dally habit of treating and operating on the eye, they will not risk their general professional and operative reputation by interfering with an organ of such delicacy.

This leads me to the second consideration of our subjectnamely, the history of the ophthalmic art.

Were I to expend several lectures on this subject, I know I conld not achieve it satisfactorily, and therefore it is my intention, on the present occasion, merely to sketch for you so much of its progress in Great Britain as may put you in possession of the means whereby it has arrived at its present high position.

It is not to be wondered at, that among the aneient Egyptians, oculists formed distinct portions of the medical profession; the general laws and customs of the country, and also the hereditary transmission of professions, led to this minute division.

It would not answer any practical result to discuss the ophthaimalogical learning of the classic authors-Hirpocrates, Galen, and Celsus, all of whom advanced this department; nor would it inprove our practical knowledge, were it possible in the time, to narrate the operative powers of Autyllus, Eresins, Paul of Egina, or ZEtius.

To the Arabians, particularly Rhazes, and Eben Sina, commonly called Avicenna, we are much indebted, as well as to Abul Kasam; but far more than history has recorded and honour awarded to them, are we indebted to the Moorish surgeons, who settled in Spain. To this people and to this age, which tre in our ignorance denominate dark, we owe much of civilization, artistic power, and literary and domestic refinement. From the glancing court of Cordova was shed a light whose reflection still lingers in the land; and though the Arabian lore may be for sotten, in a great degree, still the spirit of that mighty people lingers in the fading frescoes and the Saracenic beauties of the Alhambra, still echoes through the Bardic lore of Andalusian tales and baliads, and is imperishably enshrined in that chivalry which, despite their many faults and many privations, still exists in the Mauresco descendants of the Spanish peniusula-a chivalry which even the powerful satire and ridicule of Cervantes has not been able to sneer away.

I am the more induced to award to the Arabian surgeons this just meed of praise, because I find that much of the medical learning that distinguished the early Irish physicians was derived from them. Very probably, our early and intimate intercourse with Spain led to this. Of the Irish MSS. I have elsewhere spoken, and to attempt, or at all engage in, the question of how much we are indehted to the Arabians tor many valuable facts in ophthalmology, would be to write the history of medicine from the expulsion of that people from Europe to the beginning of the last century: this nulch I may, as an Irishman, be permitted to allude to en passant.

I have been engaged for some time (with the assistance of the best and most eritucal Irish scholars of the day) in examining our splendid collection of Irish medica! MSS., for the purpose of arriving at some knowledge of the acquaintance which our forefathers possessed with medicine; for I presume most of you are aware that that science was cultivated and taught in Ireland long antecedent to any such knowledge in the other portions of Great Britain, or indeed in any other part of north-western Europe. Without, however, going into details, I may refer you to one Irish medical work now in the collection of the Royal Irish Acadeny, the celebrated book of the O'Lees, physicians to the O'Flahertys of West Connaught, and commonly known as the Book of the Island of O'Brazil, and which was believed by the ignorant to be of divine origin. In this rou will find a system of ophthalmic surgery not only far beyond its time, but so complete even in nomenclature, that but for its time-rorn vellum, and the many historic records of it in contemporaneous works, we should be inclined to doubt its antiquity. Yet Mr. Curry, in his catalogue for the Academy, (and I fully agree with him,) assigns a date of 1314 to it. The tables of ocular diseases set forth in it go far to convince me of its being an original work, and not a translation.

I have already mentioned that diseases of the eye are very rife in Ireland, and I have endeavoured to account for some of them as arising from the present condition of certain classes of society. I may, however, mention, that through the kindness of Sir $\dot{H}$. Marsh, I some years ago became possessed of the Molyneux MSS., and among them discovered a notice of an epidemic ophthalmia which prevailed in the county Westmeath in the early part of the year 1701. It attaclsed all sexes and all ages, and left as lamentable resuits as the very worst outbreak of the Egyptian form of that disease. I could, did time permit, addnce many examples from our most ancient chronicles, to show the attention which was paid by the early bards and writers to the peculiar force and power of the eye-its character, colour, size. Thus we read, in the Book of Lecan, of Conall Cearnach, who, by means of the gloir eye which he possessed could see equaliy well by night as by day. Again: in the "Leabhar-na-Huidhre," we are told of Ingel, son of the King of the Britons, who had an eye as large as that of an ox. In otber ancient Irish MSS., we hear of Conchubbar Abhruadh Ruadh, or Connor of the R.d Eyebrows, one of the oldest pagan monarchs of Ireland; of CinuCullam, the celebrated Irish chieftain, who had a plurality of pupils in his eye; and also Eibhilin-na-Suill-Ghoin, or Ellen of the black eye and the blue eye-a peculiarity often observed in the present day.

And need I inform you that most of the holy wells of this country, of which I might relate numerous legends, are indebted for their sanctity to the virtues which they are said to possess in the cure of diseases of the eye. To these wells numberless pilgrims yearly resort, with all manner of ciseases, but chiefly those labouring under blindness, as the votive offerings luang upon the branches of the neighbouring trees still attest.

I have told you that ophthalmic surgery was much neglected by the educated general physician and surgeon in former times. This neglect was not lost sight of by the quacks and mountebanks of the last century, who palmed themselves upon the public under the name of oculists, operating at fairs and markets, and in public places, upon raised platforms, something after the manner of itinerant showmen of the present day, and whose arrival in any town or village was announced by blast of horna practice, as most of my country hearers are aware, still in rogue, with another class of practitioners, in several parts of Ireland.

Our countrymen were not behindhand in this art. An old writer of above two centuries ago, Richard Bannister, gives an account of certain Irish oculists, who erected a scaffold in the Strand, in London, and caused a trumpet to be blown before them as they went to operate. 
The most famous of all former oculists (so-called) was the Chevalier John "Taylor, "ophthalmiameter pontifical, imperial, and royal," who having amassed a fortme in England, travelled in state over the continent, in a carriage drawn by four horses, and its panels emblazoned all over with eyes, indicative of his calling. "His motto was "Qui visum, vitam dat;" and he was heralded into every city by outriders playing martial music, somewhat after the manner of a judge going to assizes. Here is his rare and curious tract-m" An exact account of 243 different diseases to which the Eye and its coverings are Exposed; all copied after nature;" and dedicated to the president and fellows of the Royal College of Physicians at Edinburgh in 1759. I will read to you a few of his high-sounding titles, which occupy no less than twenty-four lines of an octavo page..... This is not, I find, peculiar to the oculists or ophthalmiameters of the days of Chevalier Taylor. The "omnibus hoc vitium" has descended, though not quite common tousall. Here is one of the chief ophthalmic journals in Europe, and the titles of its editor occupy no less than twenty lines of exceedingly small print. Indeed, if in the same type, they would extend far beyond those of John Taylor.

In the central year of the last century, a work proceeded from the Irish press, which, as I have not seen enumerated by any of the writers on ophthalmalogy, I here bring before you:-“ A New Treatise on the Cataract or Glaucoma," (an error, however, common to his time,) " by Silvester O'Halloran of Limerick, Surgeon, 1750." It is an exceedingly ingenions volume, but we cannot now stop to discuss its merits.

The anatomical era was giving way to the eclectic; and the foundation laid by John Hunter for a proper investigation of disease was soon followed up by the work of his pupil, Baillie, on the condition of morbid structures generally. From that arose the English school of pathology and morbid anatomy, not characterized for the number of its nostrums, but for the accuracy of its observation and subsequent refinement in diagnosis. Of all modern improvemente in medicine during the present century, that of accuracy of diagnosis, the result of observation, pathology, and morbid anatomy, is the most approved and the most valuable. And of all other branches of the healing art, this faculty has been most cultivated by ophthalmic surgeons. I myself remember when nearly every inflammation of the eye was termed an "ophthalmamy," no matter what the canse, or what the structures affected ; and this was the case even in the days of Wore. The first rational attempt in Great Britain to explain and classify the various morbid changes in the eye arose with James Wardrop, formerly of Edinburgh, in his most instructive essays on "The Morbid Anatomy of the Human Eye," the first volume of which appeared in 1803, and the second, ten years later. It is not always possible to convey by words an accurate description of a diseased structure,-hence the labour and expense devoted to pathological representations in our own time; but up to the days of Mr. Wirdrop, neither with ourselves nor on the Continent had engravings of the morbid eye been attempted-at least, to any great extent; and without such, or the actual disease before you, it is totally impossible to understand diseases of the eyes. I have carefully examined most of the plates and illustrations of morbid eyes that have appeared. either in Great Britain or on the Contiment, and I must say, that beautiful as some of these certainly are, yet, in character and truthfulness, the plates to the early editions of Wardrop's book, drawn by Mr. Syme, have never been surpassed, and only equalled by those of Beer, though they were drawn by the Professor himself. In latter times, cheapness is the order of the day, and we must have engraving for the million ; the consequence is-the lithorraphic daubs you see daily. Wardrop was followed by Mr. Travers, many of whose plates are likewise very graphic, though some are too highly coloured.

In 1805, John Cunningham Saunders, who may well be styled the father of British ophthalmic surgery, founded the. London Eye Infirmary, and from him and his school have since arisen all the eminent oculists of these kingdoms. The plain commonsense, the simplicity, the critical observation-nay, the discovery, and above all, the reduction to the well-established rules of surgery, the treatment of ophthalmic diseases, which appear on every page of Saunders' writings, while they instruct, and will ever continue to instruct, all who peruse them, leave a sad and moumful impression upon the minds of those who know how early he was snatched from his labours-that he has left so little behind him; but

\section{"The good die first,}

And they whose hearts are dry as summer's dust

Burn to the socket."

Until the establishment of the London Ophthalmic Hospital, and the instruction given there by Mr. Saunders and Dr. Farre, there was no institution in these kingdoms where the student could study this most necessary department of medicine, and those who wished to inform themselves upon that subject had to go abroad for the purpose. In other conntries, ophthalmic surgery stands much higher than it does with us, because men of worth and distinguished scientific reputation have devoted themselves to it; because the different states and educating bodies upon the Continent have declared it a necessary portion of medical instruction; and separate professorships have been set apart for it, and separate degrees granted in this branch of knowledge, and because men of the highest class of mind have cultivated this art. Need I mention the names of Beer, of Scarpa, the Soemmerings, father and son ; Schmidt, Demours, Richter, Himley, Gräffe, Jäger, Rosas, Jungken, and Sichel, to establish this fact. Of the school of Vienna I have already given a description elsewhere, and therefore I need not now enlarge upon the great advantages it affords. The low condition in which ophthalmic surgery stood in England at the beginning of this century is, however, rapidly passing away. With Percival Pott, Sannders, Wardrop, Gibson, Adams, and a few others, arose a new school, from whence sprung Travers, Ware, and the late lamented Mr. Tyrrell, whose pupil I had the advantage of being, and which is now ably conducted by Messrs. Mackenzie, Lawrence, Alexander, Middlemore, Dalrymple, Guthrie, and Scott, together with Dr. Hocken, Mr. Wharton Jones, Dr. Hamilton, and a faw others. Eye infirmaries and ophthalmic institutiong are springing up in every part of England as well as the metropolis, but I regret to say that heretofore Ireland has afforded but few and meagre opportunities for studying ophthalmic diseases.

It will not do that in your daily walk through a general hospital, you are told that such and such are cases of iritis, amaurosis, or cataract. In order to study and to learn anything of such affections, you must ubserve them specially treated upon a large scale, by those who pay particular attention to such diseases. The deficiency of ophthalmic institutions in this city has long been felt by patients as well as pupils. There have been, no doubt, teachers, as well as writers, upon ophthalmic subjects - and good ones, too; but there has been no school of ophthalmalogy, no special ophthalmic hospital, and very little has been done to advance this art. During the last twenty-five years, Sir Philip Crampton, Drs. Jacob and Ryal, Messrs. Hewson and $H$. Carmichael, were the only persons who added anything to ophthalmic literature, and but two of these practised as special oculists.

Why is it, gentlemen, that highly-educated medical men now apply themselves to the study and treatment of eye diseases solely? Because the number of these diseases is so great, being many more than those that affect any other organ of the body: and because they require such peculiar modes of treatment, that any person, in good ophthalnic practice, finds all his time barely sufficient to attend the cases that present themselves. I have now endeavoured, as briefly as possible, to bring before you some few of the many practical reasons for studying eye diseases; let me add one or two more. It is, when practised with success, highly remunerative; and it is, without exception, that branch of the healing art whose success is most easily appreciated, and most justly valued by the public. The operative part of it is, when it succeeds, one of the most splendid, the most brilliant exhibitions of surgery: Take, for instance, the extraction of a cataract,- the patient is in total darkness. Years may have intervened since he has seen the familiar faces of his friends, rejoiced in the glorious light of day, felt comfort from the recognition of his home, or improved and elevated by the beauties of a landscape, and the evidence of a designing hand in all the wonder and the majesty of external nature. With little pain, you pass a knife across a portion of his eye, the curtain that hung between him and the light is suddenly withdrawn, the opacity is removed, and, in a moment, $I$ might say in the twinkling of an eye, the ephetha is spoken, and he is again restored to light and vision. If all proceeds well, great will be his joy and gratitude, and great your fame and profit.

Let me now offer a few observations upon some of the essential requisites of an oculist. An old adage affirms, that to be a good surgeon, it is necessary to possess the eye of an eagle, the hand of a lady, and the heart of a lion. In ophthalmic surgery, perhaps, we may not need the latter; our operations are often bloodless, and many of them cause little pain; but to no man more than the oculist are the first two absolutely necessary. Without delicacy of touch, and dexterity of manipulation, no man, no matter what may be his know ledge, or his other acquirements, should operate apon the living eye. Regarding the first, it is unnecessary to tell you, that clear, distinct, and accurate vision, such as man possesses when his organs of sight are in perfection, is indispensable to all who operate upon the human eye. But this is not all; it is of the highest importance that the oculist be also a good practica 
surgeon, and a well-educated physician; and to these let me add, steadiness of purpose, unwearying patience, honesty, and courage. Though I cannot dwell long, yet I cannot dwell too forcibly, upon the necessity of an acquaintance with medicine, in order to treat ophthalmic diseases with effect. Of late years, and in Great Britain in particular, we have acquired a habit of treating the human eye as if it did not form a part of the human body-as if this delicate and beautiful portion of our frame was some bottled preparation to be chemically altered during disease, by the many nostrums poured over it.

In your anatomical and your surgical lectures, you have all heard of the absolute necessity of your being acquainted with anatomy for the successful cultivation of either medicine or surgery. All that could have been offered with effect upon that subject becomes doubly applicable here. How many treat a pneumonia, diagnose an inflammation of the brain, or even remove $a$ limb, without any very accurate knowledge of the anatomy of these parts ; but you cannot diagnose or treat the diseases of the eye, or perform any of the operations upon it, without being perfectly well acquainted with the relative anatomy of each individual part; its structure, the peculiarity of its vascularity, the organization of its texture, its nervous endowment, functions, and degree of vitality, and sympathetic or actual connexion with other organs either proximate or remote.

\section{ON THE \\ RISE, PROGRESS, AND MYSTERIES} $O F$

\section{MESMERISM}

IN ATL AGES AND COUNTRIES.

\section{BY CHARLES RADCLYFFE HALL, M.D.} EXTRA-LICENTIATE OF TAE COLLEGE OF PHYSICIANS, LONDON.

\section{No. VIII.}

REMARKS ON THE FACTS OF MODERN MESMERISM-continued.

$\S 512$. Any sort of passes will cause muscular rigidity, and the same sort continued will remove this again, $(\$ 277$.

$\S 513$. Mesmerism is reflected from mirrors like light, $(\$ 459 ;)$ but, unlike the straight rays of light, it can bend round an intervening body, without losing anything of its force, ( $\$$ 343.) It required only a few seconds for this purpose in Dr. Wilson's case, (\$ 268.) Any agent which acts in straight lines, like light and heat, has its power diminished with the square of the distance from its source. Some authors seem to imply that the mesmeric agent observes this law, ( $\$ 186$.) If it does not, it has no analogy with light and heat, which do; if it does, how can it act just as strongly at a distance of three miles as when its source is nearer to its destined recipient?

\$ 514. An interesting and zealous mesmerisé, anxious to ascertain for himself whether he could feel pain, when sleepwaking, bit his own hand until blood came, (\$289.) As he felt nothing, and of course could gain no assistance from his other senses fast locked in mesmeric sleep, it is difficult to divine how he managed to guide his hand to his mouth.

\$15. Mesmeric facts have little respect for anatomy. Thus, when half only of the brain is mesmerised, the corresponding, not, as in palsy, the opposite, half of the body is affected, $(\$ 419$. In depriving parts of their sensibility, the nerves seem to have very little share in the matter. 'The gums are insensible, whilst the inside of the cheeks and lips are quite sensible, notwithstanding the same nerve of sensation supplies all, $(\$ 295$.$) A line of$ demarcation under the lower jaw cuts through the ramifications of the sensory nerves, without the slightest regard to their function, (\$295.)

\$516. The alleged effects of mesmerism on the senses are reducible to heightened sensation, diminished sensation, perverted sensation, transposed sensation, and community of sensation between patient and operator.

\& 517. We have illustrations of each of these, wonderful enough, if we take for granted the assumed unconsciousness and insensibility of the mesmerised patient in every respect, but with regard to the one sense operated on; less marvellous, if we suppose it possible for the mesmerise to be alive to all that is passing around. What proof of community of feeling is there if the patient can see the injury done to his mesmeriser, or, when blindfolded, if he has consciousness and can hear, or failing to hear, at least can suspect what is going on? Of community of smell, provided the patisnt himself can smell as well as his mesmeriser? Of com. munity of hearing, if the patient can hear? Or of taste, if sight, smell, and hearing, or any of these, are left to give information?
The examples adduced by the mesmerists are valueless, unless it can be proved that in every instance the patient was unconscious, and unable, therefore, to derive knowledge from his senses in the ordinary way. Dr. Fahnestock was perhaps not incorrect when he stated that mesmeric patients conld smell or not, just as they pleased; and the remark might be applied to all the other senses.

$\$ 518$. The effects on the senses have usually been deemed the criteria of the existence of real mesmeric somnambulism; but declining a test that would make success the only measure of the influence, it will be preferable to take for granted that every patient was in the state assumed by the mesmeriser. If it be argued that, although truly sleepwaking, a patient might not in a given case be affected to a sufficient degree to manifest all the phenomena of mesmeric somnambulism, then, we ask, until the order in which these phenomena occur has been defined, what proof that he was sufficiently affected to present any-that he was a somnambulist at all?

$\$ 519$. When it is desired to prove that the patient cannot hear, he is usually deaf enough; when it is wished to prove insensibility of the surface, he will bear pain without injury, but he generally forgets that he ought also to be deaf; he hears and answers questions. And notwithstanding the insensibility of feeling, a patient deep enough to be clairvoyant will complain that he finds the effort of seeing through the back of his head very fatiguing, $(\S 344$.

$\$ 520$. With respect to transposition of the senses: common sensibility is universal; hearing and smell, from the universality of the medium through which they are affected, are virtually, though not literally so; and taste is so much modified and assisted by smell, that it would be difficult, without intentionally preventing all aid from that sense, to obtain any evidence of transposed sensation. Vision offers us the readiest and least doubtful means for testing the existence of extreme sensibility, transposition, or community of sensation. And it is not more on account of the most marvellous of all the statements of the mesmerists having reference to this sense, than from its being a test of the alleged effects on the other senses, that clairvoyance has justly been considered the touchstone of mesmerism. If all that refers to the eye is false, there is nothing worthy of argument in what has been adduced with respect to the other senses; and if clairvoyance be true, we may admit all the rest. Clairvoyance is so highly improbable, that no reasonable person could admit it to be true on grounds that were in the slightest degree open to suspicion. Is there a single instance of success where to suspect would be impossible, to doubt, unreasonable? Mr. Townshend's case of $E$. A. is perhaps as strong as any. It is affirmed that he read a letter, previously unseen by him, in a perfectly dark closet, and that, in order to increase his perspicacity, he intentionally muflled his head in a dressing-gown. We cannot deny this, and we are constrained to believe that the narrator thinks it genuine; but it seems strange that the addition of more than a certain number of towels, on another occasion, should quite prevent his seeing, ( $\$ 341$;) that the presence of a sceptic should destroy his lucidity, $(\$ 346$;) that to read a book, it must, to a certain extent, be open, ( $\$ 343$; ) that to see distinctly with his forehead, the object must not be held too close to the forehead, ( $\$ 344 ;)$ and in cases of difficulty his electric method is very like an ingenionsly devised mode of gaining an opportunity for an unobserved peep, $(\$ 344$.$) His frontal vision through coloured lenses, however, is$ an experimentum crucis, (\$ 339.) He saw things blue when he applied a blue lens to his forehead. But he saw things not larger when he looked with his forehead through a magnifying-glass. Colour being the result of a certain impression made by luminous rays on the retina, if light could be so conveyed as to produce the sensation of colour, it could be so conveyed as to give the notion of size; the magnifying-glass should have enlarged the objects. If, as Mr. Towashend contends, the eye had nothing to do with the phenomenon, how can we account for the blue colour? If the eye was the percipient organ, how acconnt for the non-enlargement? The size of bodies, their relative position and distance, are judged by us from the visual angle made by the rays of light in entering the eye, or rather, I believe, from the situation at which the luminous rays impinge on the retina, with reference to the centre of acute vision.* The eye is constructed with express regard, and is essential, to the performance of this function. In clairvoyance, either the patient does ise the eye, in which case the rectilinear passage of light-the basis of opties-is a fallacy; or the opacity of bodies no obstacle to the passage of luminous rays, which experience contradicts; or else he sees objects, distinguishes size, and measures distance, without the use of the eye, in which case all that was bafore established in the physiology of vision must be wrong.

* See essays on Strabismus, in Mledical Gazette, for 1842, p. 713 . 